\title{
The development of polyurea greases based on paraffin-naphthenic lubricating oil VHVI-4
}

\author{
D.I. Daudi, A.Y. Kilyakova, O.A. Kalyanova, A.F. Korotaev, K.G. Aleksanyan \\ Department of Chemistry and Technology of Lubricants and Chemotology, Gubkin Russian \\ State University of Oil and Gas (National Research University), Moscow, Russia
}

\begin{abstract}
The purpose of this work was to improve the tribological characteristics and low-temperature properties of polyurea greases, as well as to expand the operating temperatures of their use. In this work, as the dispersion medium were used base oils of groups I (I-20) and III (VHVI4). Diurea was used as a thickener. The obtained samples of the lubricating greases were analyzed: penetration (GOST 32331-2013), drop-point temperature (GOST 32394-2013), colloidal stability (GOST 7142-74), tribological characteristics (GOST 9490-75), and effective viscosity at $50^{\circ} \mathrm{C}$ (GOST 26581-85). Based on the analysis of the obtained data, it was concluded that the best properties have lubricants prepared on the group IIIbase oils. To improve the low-temperature properties, it was proposed to add a $50 \%$ ester (DOTF) to the dispersion medium of greases which have better performance.As a result of work done, we concluded that the polyurea greases improved their tribological characteristics and lowtemperature properties after adding ether to VHVI-4 (1:1) as a dispersion medium.
\end{abstract}

\section{Introduction}

With the increasing load and speed of machines, the requirements for the quality of their construction materials, including lubricants, are also increasing [1]. Manufacturers are trying to improve performance to increase the service life of the equipment and its energy efficiency, as well as optimize the relationship between the price and quality of lubricants, and unify them. Lubricants, in their turn, are divided into lubricating oils, cooling mixtures, and greases. Despite the lower volume of production of greases compared to lube oils, their importance in ensuring the stable operation of machines and mechanisms is very high. The Russian Federation produces about 60 thousand tons of lubricating greases per year; most of them are prepared with a lithium thickener (68\%) [2].The Russian Federation accounts for only $3-5 \%$ wt. from the global production of lubricating greases. After analyzing the market for lithium, we can trace down a trend towards its further increase in price (an increase in demand by $240 \%$ by 2024 due to the 
growth of production of Li-ion batteries [3], and this, in its turn, will affect the inefficiency of its use as a component of a thickener for greases.

Along with this fact, it can be argued that promising components for lubricants are thickeners based on polyurea. These high-molecular compounds, containing urethane groups in their structure, are characterized by high chemical and thermal stability, mechanical stability, and good thickening capacity towards other dispersed media (Table 1).An important property of polyurea lubricants is their environmental friendliness [4]. Despite the fact that the reagents for obtaining thickeners based on polyurea-isocyanates and aminesare toxic substances, the thickener itself is not harmful and can be used for food-processing equipment.

It has also been established that polyurea greases are characterized by good pumpability, high hydrolytic and chemical stability in contact with aggressive media or water vapor, excellent anti-oxidative and mechanical stability, as well as a stable level of lubricating properties during long-term operation in a wide temperature range varying from minus $70^{\circ} \mathrm{C}$ to plus $260{ }^{\circ} \mathrm{C}[5]$.

In addition, Shell Lubricants conducted research that showed that the replacement of lithium lubricants with polyurea in various rolling bearings in the metallurgical industry resulted in a reduction in the share of replaced bearings by more than half and a reduction in lubricant consumption by $30 \%$ by weight [6].

Table 1. Comparison of properties of lithium and polyurea types of thickeners for greases.

\begin{tabular}{|c|c|c|c|c|c|c|c|c|c|c|c|c|c|c|c|c|c|c|}
\hline $\begin{array}{l}\text { Parameter / } \\
\text { thickeners }\end{array}$ & $\begin{array}{l}\text { High- } \\
\text { tempe } \\
\text { rature } \\
\text { proper } \\
\text { ties }\end{array}$ & $\begin{array}{l}\text { Low- } \\
\text { tempe } \\
\text { rature } \\
\text { proper } \\
\text { ties }\end{array}$ & $\begin{array}{l}\text { Obso } \\
\text { escer } \\
\text { e }\end{array}$ & $\begin{array}{l}\text { Meta } \\
\text { ccomp } \\
\text { tibili }\end{array}$ & $\begin{array}{l}\text { Coll } \\
\text { dal } \\
\text { stabi } \\
\text { ty }\end{array}$ & & oxi & $\begin{array}{l}\text { iAc } \\
\text { io }\end{array}$ & dhes & $\begin{array}{l}\text { Flu } \\
\text { y }\end{array}$ & & $\begin{array}{l}\text { Max } \\
\text { num } \\
\text { oad } \\
\text { capa } \\
\text { y }\end{array}$ & $\begin{array}{l}\text { Sh } \\
\text { res } \\
\text { nc } \\
{ }^{i}\end{array}$ & $\begin{array}{l}\text { ear } \\
\text { ista }\end{array}$ & $\begin{array}{l}\text { Anti- } \\
\text { fricti } \\
n \\
\text { prop } \\
\text { ties }\end{array}$ & & $\begin{array}{l}\text { nti- } \\
\text { ear } \\
\text { oper } \\
\text { es }\end{array}$ & $\begin{array}{l}\text { Gener } \\
\text { al } \\
\text { rcharac } \\
\text { teristic }\end{array}$ \\
\hline Lithium & 1,5 & 2,0 & 1,5 & 2,0 & 2,0 & & 2,0 & & 2,0 & 2 , & & 1,5 & & 0 & 2,0 & & 2,5 & 1,9 \\
\hline Polyurea & 1,0 & 1,5 & 1,5 & 2,5 & 2,0 & & 1,5 & & 2,5 & 2 , & & 3,0 & & 0 & 1,0 & & 2,0 & 2,0 \\
\hline
\end{tabular}

1.0-excellent; 2.0 -average; 3.0 - weak.

In a consequence of the above properties, one can obtain lubricating greases that can work in extreme conditions, where traditional soap lubricants are ineffective. A small difference in the cost between polyurea and lithium thickener, including longer service life, make them a more attractive lubricant from the point of view of the consumer.

A large amount of research is being conducted on polyurea lubricants. Thus, in the works $[7,8]$, the influence of the structure of the polyurea thickener on the properties of the obtained greases is considered, and it is noted that the change in rates occurs depending on the number of urea groups per polyurea molecule. 
In addition to research on the structure of a polyurea thickener and its composition, much attention is paid to the influence of dispersion media on the properties of greases.It was found that the thickening capacity of the polyurea depends on the group composition of the lube oil. Polycyclic hydrocarbons thickened heavier than paraffin-naphthenic [5]. In work [9] one can find a linear dependence of the thickening capacity of polyurea and an exponential dependence of the vaporization of plastic lubricants on the fractionation composition and the established influence of group composition on the formation of the structural framework of a urethane thickener, low temperature, and tribological characteristics of polyurea lubricants.In that work, the authors applied lube oils obtained after selective purification and hydro catalytic processes, as well as used synthetic polyalphaolefin oil.

Research of rheological and tribological properties of polyurea lubricants with the addition of esters as a dispersion medium is also of interest.In the paper [10], it is stated that these properties are determined by the interaction of thickener particles with the base oil: improved compatibility can increase the colloid stability of the lubricant, but reduce the yield strength, effective viscosity, and anti-wear properties.

However, the works about improving the low-temperature properties of polyurea lubricants by using group III base oils and esters has not been studied extensively and are of great practical interest for expanding the working range of lubricating greases based on urethane thickeners.

\section{Methodology}

To assess the consistency of the lubricant, one should use the penetration index, which is determined according to GOST 32331-2013. According to this indicator, lubricants are classified into six different types from "very fluid" to "very hard". The scope of application of greases is determined in accordance with these criteria.

An essential characteristic is colloidal stability, which is determined in accordance with GOST 7142-74.The colloid stability indicator characterizes the actions of the lubricating grease during storage and operation. The Low range of indicators negatively affects the lubrication ability, and the high range leads to delamination [11].

The drop-off temperature is a characteristic that indirectly characterizes the upper temperature limit of the grease application. It is determined according to GOST 32394-2013.

These three indicators are used to control the recipe and prepare technology.

Tribological characteristics are also important characteristics of lubricating grease. To determine the tribological characteristics, bench tests are performed on a four-ball friction machine in accordance with GOST 9490-75.Tribological characteristics show the ability of lubricating greases to protect parts from wearing and tearing up.

To determine the suitability of grease for its further use at low temperatures, its effective viscosity is determined at $-50^{\circ} \mathrm{C}$ according to GOST 26581-85.

In accordance with the purpose of the work, all these criteria were of interest for research. 


\section{Experiment}

As a dispersion medium, we considered using the base oils of groups I and III. The thickening capacity of the polyurea depends on the group composition of the lube oil. Polycyclic hydrocarbons thicken heavier than paraffin-naphthenic.VHVI-4 base lube oils (group III) have a number of advantages over I-20A (group I) lube oils such as: lower sulfur content, higher viscosity index, and bigger amount of saturated hydrocarbons (Table 2). All these criteria effect the best serviceability of polyurea grease prepared on VHVI-4 lubricating oil (group III) (Table 3).

Table 2. Advantages of group III base lube oils over group I base lube oils.

\begin{tabular}{ll}
\hline \multicolumn{1}{c}{ Distinctive features of the alternative base oil } & \multicolumn{1}{c}{ Properties } \\
\hline Higher viscosity index & $\begin{array}{l}\text { Optimal lube oil film thickness at both low and } \\
\text { high temperatures }\end{array}$ \\
Low-temperature performance characteristics & Maintaining fluidity at low temperatures \\
Low evaporation rate & Lower lube oil consumption \\
$\begin{array}{l}\text { Lower friction coefficient (when esters are added } \\
\text { to the lube oil) }\end{array}$ & $\begin{array}{l}\text { More steady molecular structure of synthetic lube } \\
\text { oil: reduced internal friction coefficient }\end{array}$ \\
$\begin{array}{l}\text { High thermal-oxidative stability due to lower } \\
\text { sulfur content }\end{array}$ & $\begin{array}{l}\text { Slowing down the aging process of lube oil in } \\
\text { contact with oxygen molecules }\end{array}$ \\
\hline
\end{tabular}

Table 3. Comparison of properties of polyurea lubricants on the basis of different dispersion media (16\% thickener) without additives.

\begin{tabular}{|c|c|c|c|c|c|c|c|}
\hline \multirow{2}{*}{ Grease } & \multirow{2}{*}{$\begin{array}{l}\text { Penetration at } \\
25^{\circ} \mathrm{C}, \mathrm{mm}^{-1}\end{array}$} & \multirow{2}{*}{$\begin{array}{c}\text { Effective } \\
\text { viscosity at } \\
\text { minus } 50^{\circ} \mathrm{C}, \\
\mathrm{PA}^{*} \mathrm{~s}\end{array}$} & \multirow{2}{*}{$\begin{array}{l}\mathrm{KS}, \\
\text { mass } \\
\% .\end{array}$} & \multicolumn{3}{|c|}{$\begin{array}{l}\text { Tribological } \\
\text { properties }\end{array}$} & \multirow{2}{*}{$\begin{array}{c}\text { Drop-off } \\
\text { temperature, }{ }^{\circ} \mathrm{C}\end{array}$} \\
\hline & & & & $\begin{array}{l}\mathrm{P}, \\
\mathrm{N}\end{array}$ & $\begin{array}{c}\mathrm{P}_{\mathrm{w}}, \\
\mathrm{N}\end{array}$ & $\begin{array}{l}\mathrm{D}_{\mathrm{p}} \\
\mathrm{mm}\end{array}$ & \\
\hline $\begin{array}{c}\text { Polyurea } \\
\text { lubricant based } \\
\text { on I-20 A (group } \\
\text { I) }\end{array}$ & 271 & 2308 & 9,3 & 100 & 150 & 0,72 & 160 \\
\hline $\begin{array}{c}\text { Polyurea } \\
\text { lubricant based } \\
\text { on VHVI } 4 \\
\text { (group III) }\end{array}$ & 142 & 1413 & 7,5 & 275 & 250 & 0,67 & 260 \\
\hline
\end{tabular}

Previous works based on the research about polyurea greases based on lubrication oil have shown that with an increase in the content of resinous-asphaltene substances in the dispersion base, the thickening capacity of diurea worsens, but the extreme pressure stability and anti-wear properties increase.The recommended content of polycyclic aromatic hydrocarbons in the lube oil base should not exceed $2 \%$ [12].

Semisynthetic lubricating oils (VHVI-4), which may be used as a dispersion medium, have low evaporation and pour point, high thermal stability, good antioxidant stability, and high viscosity index.Due to these properties, the temperature ranges of diurea greases obtained are significantly broader. 
The samples obtained were prepared on a standard laboratory setup, which consisted of an electric heater, a porcelain cup, a mixing device, and a thermometer. Thermomechanical dispersion of the dispersed phase into the dispersion medium is carried out under continuous heating and mechanical mixing, as well as it has to be performed under atmospheric pressure. The thickener preparation consisted of mixing $9 \%$ by weight of rhodamine and $7 \%$ by weight of polyisocyanate, with no aniline added, so that the resulting plastic lubricant turned out to be more environmentally friendly than analogues that included aniline (Figure 1).

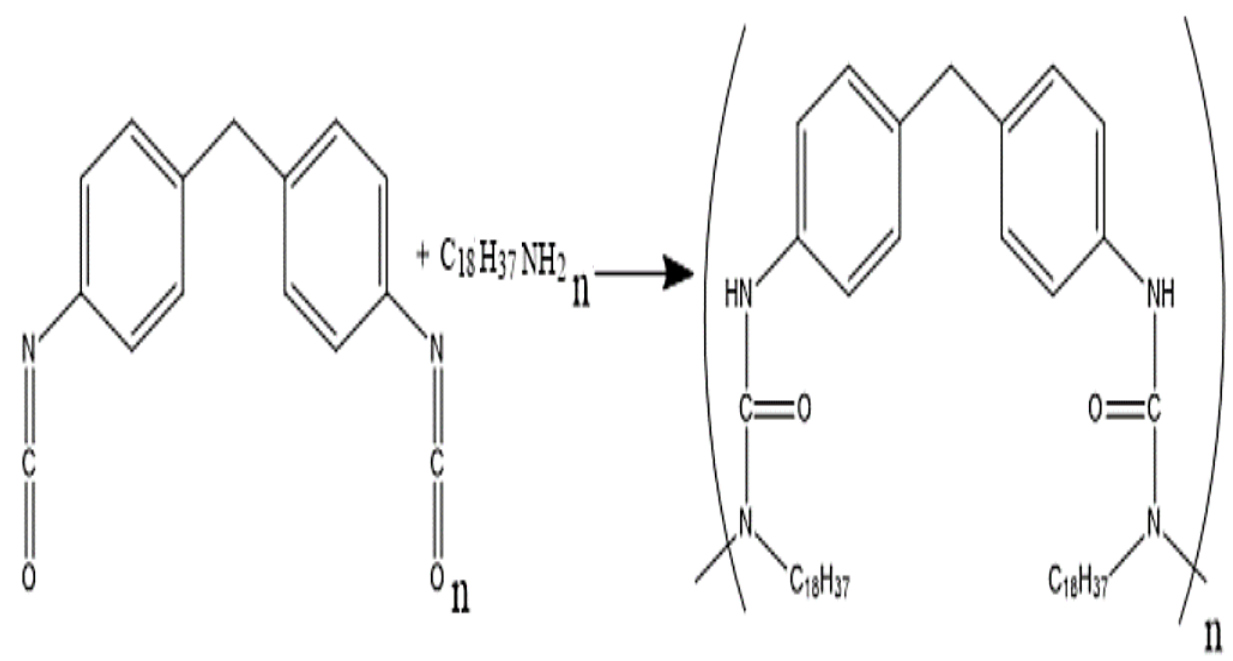

Fig. 1. The receipt of the thickener - diurea.

Half of the calculated amount of dispersion medium was mixed with the required amount of polyisocyanate and heated at $80^{\circ} \mathrm{C}$ for 15 minutes. At the same time, rhodamine was added to the other half of the lube oil base, heated up to $90^{\circ} \mathrm{C}$ and kept at this temperature for 15 minutes.Then, with constant stirring, the first mixture was added to the obtained mixture and stirred for 25 minutes at $120-125^{\circ} \mathrm{C}$.After the time for fast cooling, the prepared mixture was unloaded onto a baking tray and distributed into a thin layer.The cooled mass was put through a manual homogenizer.

The resulting samples of obtained lubricating grease were analyzed and the following indicators were identified: drop-off temperature, penetration, colloidal stability, effective viscosity at $-50^{\circ} \mathrm{C}$, and tribological characteristics.

\subsection{Adding DOTF ester}

It is known that due to the presence of polar groups in the composition of esters, they latter have better adhesion and lubricating properties than paraffin hydrocarbons.in addition to that fact, ester compositions in the molecules of group ii and iiibase oils, increase their portability to additives.esters, also, have low pour points.based on the advantages shown, it was decided to determine the esters effect on the properties of polyurea greases. It was proposed to prepare lubricating greases on the dos and dot dispersion media and compare those with the lubricant based on vhvi-4 (table 4). 
Table 4. Comparison of properties of polyurea lubricants prepared on the basis of DOS and DOTF esters $(16 \%$ thickener $)$ without additives.

Ether

According to the test results, the best properties were obtained from a lubricating grease prepared on DOTF as a dispersion medium.

Since 2019, the SIBURCompany has been engaged in the production of this ester in Russia.The advantage of dioctyl terephthalate is the absence of carcinogenic effects and toxicity, which inhibited the use of its predecessor, i.e. dioctyl phthalate (DOF), which is a mixture of three isomers.

An important role in the production of DOTF is the availability of raw materials. Now it is necessary search for cheaper technologies for production of DOTF; for example, secondary polyethylene terephthalate (PET) can be used as a source of terephthalic acid, the recycling of which is a pressing environmental issue. Also, the technology for obtaining dioctyl terephthalate based on by-products (RF Patent 2404156, 2009) has been developed based on bottom products of rectification of 2-ethylhexanol (BPREN) and water cut technical terephthalic acid.

Thus, it was proposed to add this easter at a $50 \%$ concentration to improve the tribological and low-temperature properties of polyurea greases without worsening the drop-off temperature (Table 5).

Table 5. Comparison of properties of polyurea lubricants on the basis of different dispersion media (16\% thickener) without additives.

\begin{tabular}{|c|c|c|c|c|c|c|c|}
\hline \multirow{2}{*}{ Grease } & \multirow{2}{*}{$\begin{array}{l}\text { Penetration at } \\
25^{\circ} \mathrm{C}, \mathrm{mm}^{-1}\end{array}$} & \multirow{2}{*}{$\begin{array}{c}\text { Effective } \\
\text { viscosity at } \\
\text { minus } 50^{\circ} \mathrm{C} \text {, } \\
\text { PA*s }^{*}\end{array}$} & \multirow{2}{*}{$\begin{array}{l}\mathrm{KS}, \\
\text { mass } \\
\% .\end{array}$} & \multicolumn{3}{|c|}{$\begin{array}{l}\text { Tribological } \\
\text { properties }\end{array}$} & \multirow{2}{*}{$\begin{array}{c}\text { Drop-off } \\
\text { temperature, }{ }^{\circ} \mathrm{C}\end{array}$} \\
\hline & & & & $\begin{array}{l}\mathrm{P}_{\mathrm{c}}, \\
\mathrm{N}\end{array}$ & $\begin{array}{c}\mathrm{P}_{\mathrm{w}} \\
\mathrm{N}\end{array}$ & $\begin{array}{l}\mathrm{D}_{\mathrm{p}} \\
\mathrm{mm}\end{array}$ & \\
\hline $\begin{array}{c}\text { Polyurea grease } \\
\text { based on VHVI } 4 \\
(100 \%)\end{array}$ & 142 & 1413 & 7,5 & 275 & 250 & 0,67 & 260 \\
\hline $\begin{array}{c}\text { Polyurea grease } \\
\text { based on DOTF } \\
(100 \%)\end{array}$ & 154 & 985 & 3,4 & 231 & 210 & 0,51 & 190 \\
\hline $\begin{array}{c}\text { Polyurea grease } \\
\text { based on VHVI } 4 \\
(50 \%)+\text { DOTF } \\
(50 \%)\end{array}$ & 147 & 1210 & 6,3 & 254 & 233 & 0,62 & 240 \\
\hline
\end{tabular}




\section{Conclusion}

Based on the analysis of the data obtained, we concluded that greases prepared on group III lubricating base oils have better properties than their analogues prepared on group I lube oils.It was also proved that lubricating greases prepared on the DOF are inferior to their analogues welded on the basis of DOTF.The optimal concentration of the dispersion medium was selected at 50\% DOTF / 50\% VHVI-4. After involving the ester to the composition of a polyurea grease, its low-temperature properties and tribological characteristics have improved due to the polarity of the esters and, as a result, due to their better adhesion.

\section{References}

1. D. I. Daudi, A. Y. Kilyakova, B. P. Tonkonogov, O. A. Kalyanova Influence of DOTF on properties of polyurea plastic lubricants. NefteGaz-2020, 3(5)

2. D. Bannikov Plastic relocation. Sibirskaya Neft, 6(123), 34-39 (2015)

3. Deutsche Bank/ Markets Research/Industry/Lithium 101-2016. - P. 4.

4. Garshin M.V., Kilyakova A.Y. Influence of the composition of hydrocarbon base oils on the properties of low-temperature polyurea lubricants. Gubkin Russian State University of Oil and Gas (NRU)

5. A. M. Danilov Grease based on the polyuria, 68 p. (Moscow: Tsniiteneftekhim, 1995)

6. Mobil SHC Polyrex. Mobil.

7. L. Liu, H. W. Sun Impact of polyurea structure on grease properties. Lubrications Science, V(22,I(9)), 405-413 (2010)

8. Z. Gaiqing, Z. Suixin, W. Xiaobo, L. Weimin The relationships of thickener structures and properties of polyurea grease. Lubrication Engineering, (2012)

9. M. V. Garshin, Ya. V. Porfiriev, V. A. Zaichenko, S. A. Shuvalov, D. S. Kalybelsky, P. A. Gushchin, V. A. Vinokurov Influence of the composition of hydrocarbon base oils on the properties of low temperature polyurea lubricants. Petrochemistry, 57(6), 800-804 (2017)

10. Yu. M. Maksimova, A. S. Shakhmatova, S. O. Ilyin, O. A. Pakhmanova, A. S. Lyadov, S. V. Antonov, O. P. Parenago Rheological and Tribological Properties of Lubricating Greases Based on Esters and Polyurea Thickeners. Petroleum Chemistry, 58, 10641069 (2018)

11. Y. L. Ishchuk The Composition, structure and properties of greases, 512 p. (Kiev: NaukovaDumka, 1996)

12. Ya. I. Borisenko, Yu. L. Ishchuk, Z. M. Nikishina, F. Z. Voznyuk CHTFO, 4, 26-28 (1989) 